Ram S. Ravindran MD, Gregory C. Zandstra MD, Oscar J. Viegas MD

\title{
Postpartum Headache Following Regional Analgesia; A Symptom of Cerebral Venous Thrombosis
}

In this report we describe a patient who developed severe headache following uneventful continuous epidural analgesia for labour and delivery. Initially it was thought that she had a spinal headache. However, with the aid of Magnetic Resonance Imaging the diagnosis of cerebral venous thrombosis was later established. The entity of cerebral venous thrombosis, its manifestation, pathology, diagnosis and treatment are discussed.

The use of epidural analgesia to provide pain relief for labour and delivery has become increasingly popular. During the placement of an epidural needle or the catheter, recognizable inadvertent dural puncture may occur in 0.5 to 10 per cent of cases depending on the experience of the anacsthetist. ${ }^{1,2}$ Unrecognized dural puncture occurs in about 1.5 per cent of cases. ${ }^{3}$ Thus, it is not uncommon for a patient to develop "spinal headache" following uneventful epidural analgesia. Before treating the headache in such patients one has to consider other conditions which could also produce headache. In this report, we describe a patient whose headache was thought to be a spinal headache and who was unsuccessfully treated with autologous epidural blood patch (EBP). However, the cause of her headache was subsequently diagnosed as thrombosis of the superior sagital sinus.

\section{Case report}

An 18-year-old $94 \mathrm{~kg}$, gravida 1, para O, ASA Physical Status Class I patient was admitted at 39 weeks of

\section{Key words}

ANAESTHESIA: obstetric; ANAESTHETIC TECHNIQUES: epidural, spinal, lumbar; COMPLICATIONS: headache, seizure, thrombosis, cerebral venous.

Department of Anaesthesia, Indiana University Medical Center, Indianapolis, In 46223.

Send correspondence to: Dr. R.S. Ravindran. gestation for labour and delivery. Her past medical history included asthma, frequent sinus headaches, and ear infections. Her prenatal medications included vitamins and iron supplements. She had gained $30 \mathrm{~kg}$ during her recent pregnancy. A 24-hour urine sample revealed $330 \mathrm{mg} \cdot \mathrm{L}^{-1}$ protein. There was mild oedema in both the lower extremities. Her tendon reflexes were normal and there was no clonus. Her blood pressure was $110 / 80$ $\mathrm{mmHg}$. The rest of her physical examination was normal. For labour pain relief she requested intermittent lumbar epidural analgesia (ILEA). Under sterile conditions, utilizing the loss of resistance technique, a 17 SWG epidural needle was inserted into the $\mathrm{L}_{3}-\mathrm{L}_{4}$ interspace on the third attempt. An epidural catheter was then inserted through the needle. On aspiration of the catheter there was no evidence of subarachnoid or intravascular entry. Following a negative test dose of 0.5 per cent bupivacaine with 1:200,000 epinephrine ( $3 \mathrm{ml})$, the epidural analgesia was maintained with intermittent epidural bolus injection of 0.375 per cent bupivacaine $(8-10 \mathrm{ml})$. As the progress of labour was slow, pitocin augmentation was initiated and she delivered a healthy infant in four hours. Two days later she was discharged from the hospital. Seven days following the delivery, she presented to the emergency room complaining of occipital and frontal headache, nausea and vomiting. She stated that she developed the headache the day following her discharge from the hospital and it progressively became worse. She claimed that the headache became more intense on assumption of the standing position. Though there was no obvious dural entry during either the placement of the needle or the epidural catheter, and since multiple attempts had been made at the time of placement of the needle, it was felt that her headache could have resulted from an unrecognized puncture of the dura.

She was offered an autologous EBP therapy, but she elected to try conservative therapy for a few more days. Two days later she again presented to the emergency room with similar complaints as described earlier. $A n$ autologous EBP was done with $10 \mathrm{ml}$ blood and she soon 
felt better. However, two hours later, she experienced relapse of the headache. She was admitted to the hospital for intravenous fluid therapy. Her headache persisted the next day and she was given analgesics for pain relief. On that day, multiple attempts at placement of an epidural needle for EBP were made without success. The next day she was given a second autologous EBP. She immediately felt better. Two hours later she was completely relieved of the headache. However, she was very lethargic and apathetic, had a mild elevation of her body temperature $\left(38^{\circ} \mathrm{C}\right)$ and stated that she was feeling numb in her fingers and legs. A few hours later, while attempting to go to the bathroom she fell down. At that time physical examination revealed inability of the patient to bear weight on her left lower extremity. A neurological examination done by a neurologist revealed no positive localizing findings. He suggested that her symptoms could be a form of conversion reaction. He recommended a psychiatric evaluation and a computerized tomographic (CT) scan to rule out any space occupying lesions.

The following morning she had an episode of grand mal seizures. The patient did appear post-ictal but was responsive. Neurological examination was normal. Laboratory tests were normal except for a slightly elevated alkaline phosphatase of $195 \mathrm{mIU} \cdot \mathrm{ml}^{-1}$ and fibrinogen of $505 \mathrm{mg} \cdot \mathrm{dl}^{-1}$. The magnesium concentration was 1.7 meq $\cdot \mathrm{L}^{-1}$ and she was given magnesium sulphate $2 \mathrm{~g} I V$. Her PT, PTT and fibrin split products were within normal limits. The CT scan was normal. However, an EEG revealed focal slowing in the right frontal and temporal regions. Later that evening she had another episode of generalized seizure activity. She was treated with phenytoin sodium and phenobarbital IV. Fundal examination revealed mild bilateral papilloedema. A lumbar puncture showed an opening cerebrospinal fluid (CSF) pressure of $26 \mathrm{~cm}$ of water and it was xanthochromic. A gram stain for bacteria was negative. The following evening the patient developed status epilepticus and required emergency tracheal intubation and mechanical ventilation of the lungs. However, her vital signs and oxygenation were normal.

Further investigation with magnetic resonance imaging (MRI) revealed a region of increased $T_{-1}$ signal involving the entire superior sagittal sinus consistent with the diagnosis of dural sinus thrombosis. Anti-seizure medications and antibiotic therapy were continued. Her seizure activities stopped. She was conscious and responded to questions appropriately. She was given low-dose heparin (5000 IU.12 hr) and aspirin to prevent leg vein thrombosis. Three days later her tracheal tube was removed. Thereafter, her neurological signs and symptoms showed remarkable improvement every day. A week later she had only mild weakness in both lower extremities and could walk by herself without assistance. Ten days following her admission she was discharged from the hospital. She was advised to continue taking the anti-seizure medica. tions and aspirin. Her fibrinogen concentration remained elevated $\left(502 \mathrm{mg} \cdot \mathrm{dl}^{-1}\right)$. A repeat MRI showed partial canalization of the sinus thrombus.

\section{Discussion}

The differential diagnosis of headache following uneventful intermittent or continuous epidural analgesia should include stress-induced headache, unrecognized subarachnoid puncture, relapse of a migraine headache, meningitis, preeclampsia, and the occasional presence of cerebral venous thrombosis. The previous medical history, the location of the spinal headache, and the variation in intensity of the headache with a change of position will rule out stress-induced and migrainous headaches. $\mathrm{Pa}$ tients with preeclampsia may show other signs of that disease. However, it is not easy to distinguish the headache due to cerebral venous thrombosis.

Cerebral venous thrombosis (CVT) was first described in 1962. ${ }^{4}$ It involves spontaneous thrombosis of the cerebral veins or venous sinuses. Most often, it occurs within two weeks following delivery but it has been reported to occur even before delivery. The incidence of CVT is 1:3000 pregnancies and it seems to be more common in developing countries. ${ }^{5}$ The diagnosis of CVT is based on the appearence of headache, focal neurological signs and seizures. ${ }^{6}$ Frequently, the neurological signs change. The patient is generally lethargic and apathetic. Papilloedema is not prominent. The platelet count and fibrinogen levels are increased. 5 The EEG may show slowing of cortical activity and the CT scan is negative. However, contrast CT scan and MRI may show abnormalities. ${ }^{7,8}$ The venous phase of the cerebral angiogram may show abnormalities. ${ }^{9}$ However, this is an invasive technique. Other conditions that may mimic CVT include cerebral haemorrhage, eclampsia, and cerebral arterial thrombosis."

The treatment of patients with CVT involves supportive therapy and administration of anti-seizure medication. The administration of heparin is controversial as it may cause cerebral, uterine and gastric bleeding. ${ }^{5,10}$ Surprisingly, these patients recover spontaneously and rapidly with no or minimal neurological disability. It is believed that the pathogenesis is from venous stasis, endothelial damage, and increased coagulable state that exist during the peripartum period. ${ }^{4}$ In some patients this condition may be associated with or followed by leg vein thrombosis or pulmonary embolism. In recent reports some of these patients with CVT had received regional analgesia. ${ }^{7.8}$ However, many more cases of CVT have occurred in patients who did not receive regional analgesia. 5 
The cause of headache in a postpartum patient who has received spinal or epidural analgesia for delivery or tubal ligation, is likely to be considered as "spinal headache." Before the development of seizures or neurological signs it is difficult to distinguish headache of CVT from ordinary spinal headache. However, there are some distinguishing features of CVT: the headache seems to be throbbing in nature, accentuated by movement of the head and assumption of the sitting position, and may be associated with nausea and vomiting. The patient may manifest significant lethargy, a feeling of numbness and focal non-specific weakness. In some cases there may be mild elevation of body temperature. In the presence of atypical "spinal headache" following spinal or epidural analgesia, MRI may be used to rule out the possibility of CVT.

As spinal headache is much more common than CVT the headache of CVT is likely to be treated with EBP. Interestingly, the headache often improves transiently following EBP. Though inadvertent use of EBP has not affected the clinical outcome, it may be implicated if neurological deficit results. ${ }^{7.8}$

In this report we have described a postpartum patient who developed severe headache following uneventful epidural analgesia for labour and delivery. With the aid of MRI it was later realised that the headache resulted from superior sagital vein thrombosis.

\section{References}

1 Abouleish E, Vega SD, Blendinger I. Long-term follow-up of epidural blood patch. Anesth Analg 1975; 54: 459-63.

2 Crawford JS. The second thousand epidural blocks in an obstetric hospital practice. Br J. Anaesth 1972; 44: 1277-87.

3 Ravindran RS, Albrecht $W H$, Tasch $M$. Low pressure headache following successful continuous lumbar epidural analgesia. Anesth Analg 1980; 59: 799-800.

4 Kendall $D$. Thrombosis of intracranial veins. Brain 1948; 71: 391-8.

5 Srinivasan $K$. Cerebral venous thrombosis in pregnancy and puerperium. Angiology 1983; 34: 731-46.

6 Lorincz $A B$, Moore RY. Puerperal cerebral venous thrombosis. Am J Obstet Gynecol 1962; 83: 311-8.

7 Younger D, Jones MM, Adenwala, Citrin A, Joyce $T H$. Maternal cortical vein thrombosis and the obstetric anesthesiologist. Anesth Analg 1986; 65: 1007-12.

8 Gewirlz EC, Costin MC, Marx GF. Cortical vein thrombosis may mimic postdural puncture headache. Regional Anesthesia 1987; 12: 188-90.
9 Cross $J N$, Castro PO, Jennet WB. Cerebral strokes associated with pregnancy and puerperium. Br Med J 1968; 3: 214-8.

10 Fairburn $B$. Intracranial venous thrombosis complicating oral contraception, treatment by anticoagulant drugs. $\mathrm{Br}$ Med J 1973; 2: 647-51.

\section{Résumé}

On décrit dans ce papier le cas d'une patient qui a développé une céphalée sévère après une analgésie épidurale continue sans problème lors du travail et de l'accouchement. Au début on pensait que la douleur était d'origine rachidienne, cependant avec l'aide de la résonance magnétique le diagnostic d' une trombose cérébrale veineuse fur plus tard établi. La thrombose veineuse cérébrale et ses manifestations, pathologie, diagnostic et traitement sont discutés. 